\title{
Facebook Community and Disclosure Behaviours
}

\author{
Jin Kuan Kok, Wan Ying Lee, and Shue Ling Chong
}

\begin{abstract}
Facebook has become a huge virtual community with millions of members. This paper examines the perceptions of community and disclosure behaviours among Malaysian Facebook users. Quantitative data was collected via an online survey. Chi-square was run to find the association between these two aspects. Findings show that the participants were cautious about their Facebook disclosures. Though they believe the Facebook community to be neither stable, nor realistic, they thought it detrimental to share real problems with friends known only on Facebook; and they preferred to remain anonymous; however, a high percentage of them agreed that they had a sense of belonging to this Facebook community.
\end{abstract}

Index Terms-Facebook, Facebook community, online community, trust and disclosure in Facebook.

\section{INTRODUCTION}

Facebook has captured some basic human needs, the needs of wanting to be connected and being able to share with friends. Thus it has become one of the most popular and frequently used online social networking site. The need to be connected and to share with friends belongs to the relational aspect of social life. It allows information sharing and the pursuit of knowledge [1]; it also gives a platform for university students to get updated [2]. It has attracted massive memberships and has become a new mode of communication Is was also found to be a tool for relationship and identity building in the context of Malaysia [3 ].

Blanchard and Markus [4] suggested that the use of Facebook exhibits some characteristics of community-like behaviours such as feelings of membership, feelings of influence and integration aspects whereby participants feel their needs are met. However, Zygmunt Bauman [5] uses Fluid Modernity to describe the phenomenon of post-modernity. Some of the characteristics of this metaphor of fluid modernity are transience in human bonds, instability, insecurity exhibited especially in a high tech communication society. Does this apply to the Facebook community? Blanchard and Markus [4] have identified the feeling of belonging to and identifying with are necessary for the establishment of trust in a virtual community. Do Facebook users in Malaysia feel that they belong to this Facebook community and how do they demonstrate this sense of belonging in their Facebook disclosure behaviours?

This paper examines these issues through a survey study of Facebook users in Malaysia to investigate their disclosure

Manuscript received May 8, 2014; revised July 7, 2014.

J. K. Kok and W. Y. Lee are with the Department of Psychology and Counselling, Faculty of Arts and Social Science, University Tunku Abdul Rahman, Kampar Campus, Malaysia (e-mail: kokjk@utar.edu.my, lwying@utar.edu.my).

S. L. Chong is with University Putra Malaysia, Malaysia (e-mail: shueling@gmail.com). behaviour, and to find out to what extent they feel that they belong to the Facebook community. It will help us to better understand the kind of community in which our young people are so passionately involved.

\section{LITERATURE REVIEW}

\section{A. What is Meant by Community}

Toennies [6] has distinguished two types of community: Gemeinschaft and Gesellschaft community. Those two terms are from German. The former, which is based on locality or kinship, and took a long time and effort to develop in a natural setting such as in a neighbourhood, where people knows each other. People feel a sense of belonging as they are either like-minded or like-behaving. This community focuses on sameness, the similarities and mutuality of their lives. Safety, security and strong sense of belonging are some of its characteristics. Gesellschaft, on the other hand emphasises on individuals' interests and autonomy. A Gesellscharft society involves individuals' effort and choice to achieve status, for example through education attainment. Durkheim 1951 in [7] gave different typologies to explain the ways communities provide structure and guidelines for its members so that they feel regulated and integrated. To Durkheim, 'community' remains a sociological construct of regulation. If we adopt Toennies's definition of community, the Gemeinschaft community is replaced by the Gesellschaft community as society advances. Brint [7] characterises the former with fewer members, familial and community emotional bonds, whereas the latter is characterised by larger numbers of members, rules to overcome, distrust and regulated competition. Individuals are given more freedom; however, they have to take more risks in everything they do. They thus do not have a structure for protection or security. Bauman describes it as the emancipation of individuals. Therefore a growing sense of insecurity and taking more responsibility for one's actions is the consequence of the ambivalence of modern individuals. In Bauman's term "trading off security for freedom" [8]. In a Gesellschaft (civilized) society, community may come in different shapes as long as the dimensions of membership, influence, support and emotional connection are present [1] However, how true is it that a virtual community is possible using Facebook? What are the challenges faced?

\section{B. Facebook Community}

Brint [7] criticised Toennies' definition of community as insufficient to define the contemporary concept of community when advanced technologies are integrated in information and communication modes which are not confined to geographical or social mobility boundaries. He proposed a more generic definition of community. His 
definition includes the motives of interaction. Shared common activities or beliefs are the motivated factors that bring people together. Therefore it is possible to have tens of thousands of people drawn to a similar activity due to similar beliefs or personal concerns. Therefore, the motives for interactions become centrally important and sustain the sense of community. This is a broader definition of community that is primarily based on shared values and the involvement in other people lives, such as the case of work related groups or voluntary interest organizations. It thus becomes a choice based community. This definition of community includes social relationships, and self-seeking behaviour as a motive for interaction.

Feelings of trust and a sense of belonging are the main characteristics for community building. Facebook seems to be able to give a sense of belonging as the users are able to identify memberships by common interests and the online activities involved. Metzger [9] identified trust as an issue in electronic communication. High levels of trust are necessary for tight knit community [6]. Higher trust levels will lead to higher levels of social interactions [10]. Putnam's concepts of trust and reciprocity have been identified by Norris as facilitating factors in social relationship [11] However, can it be realistic to be part of a network with millions of people and still be able to establish trust with all of them. Some researchers found that the size can be an issue in establishing trust within a community.

The design of Facebook has many features to facilitate communication and interaction. Much personal information disclosure is encouraged. Users may unconsciously disclose personal information when they fill up the Facebook profile or apply to play a Facebook game. Because of default settings, all information shared or posted becomes instantly accessible to anyone, including strangers. The "wall" in Facebook which is a public domain provides personal information. Moreover, online interaction will automatically keep a record which can be traced and retained. Pictures posted are tagged and shared by friends of common friends whom we may not even aware. Those personal pictures or any personal information, if taken out of context, may have unintended consequences and may even jeopardise career opportunities [12]. Users are thus exposed to advertisement companies, unknown online lurkers, or stalkers who passively view the Facebook information without participation [13]; hackers or identity theves may exploit it and people may be subjected to cyberbullying [14]. There is no guarantee on safety even when users set up security. Dwyer [10] stated privacy within social networking sites is not to be expected. Users do not have the power to control the safety of the information they post on Facebook.

Besides the above mentioned Facebook settings related to disclosure, there are other issues such as the nature of this virtual community which is highly flexible and self-interest oriented. The flexible design of Facebook does not have boundaries. The entrance and exit are kept wide open. People come and go in an entirely free flow. This high flexibility allows anyone to add or to delete friends or groups anytime. It poses unexpected opportunities and possibly unintended consequences. On one hand people seems to have the autonomy to pick and choose friends, but they are also subject to being chosen or deleted by others. Therefore there is an absence of obligation or moral responsibility. A sense of unstable relationship and insecurity is inevitable. Thus people have to safeguard themselves by using nicknames, open different accounts for various purposes, customize the security setting and so forth. There is a sense of nonymous status (as is opposed to anonymous) being exposed to people we don't even know. The formation process of the virtual community does not require much effort to cultivate the same relational aspects as the historical Gemeinschaft community discussed earlier. There is no grounded location and no pre-conditions are required. The factors that motivate the participation of Facebook may be entirely oriented by self-interests. Therefore the kind of virtual community and the perception of the sense of belonging to this community is the focus for this study.

\section{METHODOLOTY}

A total of 457 participants $(42.2 \%$ males and $57.8 \%$ females) aged between 16 to 65 years old from all the states of Malaysia (Peninsula and East Malaysia), but mostly were from Perak $(27.6 \%)$, Selangor $(27.1 \%)$ and Wilayah Persekutuan (14.7\%). Majority of participants were between 19 to 28 years old.

An online survey entitled 'The Use of Facebook' was conducted via UTAR Opinion Poll. Questions related to disclosure behaviour, and the perceptions about the Facebook community were posted online. Five questions on Facebook disclosure were adapted from Wheeless and Grotz's Revised Self-Disclosure Scale [15]. This scale measures self-disclosure behaviour across five dimensions intent, amount, valence (positive or negative), depth and honesty, using Likert scale, ranging from 1 (Strongly Disagree) to 5 (Strongly Agree). Only one question from each dimension was taken to measure self-disclosure on Facebook in this study.

Another set of questions was related to perception of the Facebook community. Participants were asked to indicate if they agree with the various descriptions of the virtual community. Response format was recorded in dichotomous form (Yes vs. No).

\section{FINDINGS}

To investigate the relationship between characteristics of the Facebook community and types of self-disclosure, Chi-square Test for Independence was run. As seen in Table I below, results showed significant associations between Facebook community characteristics and types of self-disclosure.

In summary, whether participants were more intentional or less intentional in their disclosures, disclosed more positively or negatively, disclosed more intimately or less intimately, were honest or less honest in their Facebook disclosure, they were all more likely to agree that Facebook was not a stable community. 
TABLE I: RESULTS OF CHI-SQUARE TEST FOR INDEPENDENCE $\left(X^{2}\right)$ BETWEEN FACEBOOK COMMUNITY CHARACTERISTICS AND DIMENSIONS OF SELF-DISCLOSURE

\begin{tabular}{|c|c|c|c|c|c|c|c|c|c|c|c|c|c|c|c|c|}
\hline \multirow{2}{*}{$\begin{array}{l}\text { Facebook } \\
\text { Community }\end{array}$} & & \multicolumn{3}{|c|}{ Intent (\%) } & \multicolumn{3}{|c|}{ Amount (\%) } & \multicolumn{3}{|c|}{ Valence (\%) } & \multicolumn{3}{|c|}{ Depth (\%) } & \multicolumn{3}{|c|}{ Honest (\%) } \\
\hline & & Yes & No & $x^{2}$ & Yes & No & $x^{2}$ & Yes & No & $x^{2}$ & Yes & No & $x^{2}$ & Yes & No & $x^{2}$ \\
\hline \multicolumn{17}{|l|}{$\begin{array}{l}\text { Stable } \\
\text { Community }\end{array}$} \\
\hline & Yes & 35.2 & 18.5 & $10.731^{* *}$ & 37.2 & 29.4 & 2.412 & 38.2 & 25.3 & $8.799 * *$ & 41.5 & 27.2 & $8.874^{* *}$ & 36.4 & 26.7 & $4.979 *$ \\
\hline & No & 64.8 & 81.5 & & 62.8 & 70.6 & & 61.8 & 74.7 & & 58.5 & 72.8 & & 63.6 & 73.3 & \\
\hline \multicolumn{17}{|l|}{ Unrealistic } \\
\hline & Yes & 69.6 & 84.3 & $8.976^{* *}$ & 70.8 & 73.8 & 0.400 & 66.5 & 78.8 & $8.693^{* *}$ & 67.7 & 75.2 & 2.686 & 71.5 & 74.5 & 0.517 \\
\hline & No & 30.4 & 15.7 & & 29.2 & 26.2 & & 33.5 & 21.2 & & 32.3 & 24.8 & & 28.5 & 25.5 & \\
\hline \multicolumn{17}{|l|}{$\begin{array}{l}\text { Unbeneficial } \\
\text { to Share }\end{array}$} \\
\hline & Yes & 67.6 & 81.5 & $7.679 * *$ & 69.0 & 71.5 & 0.255 & 63.7 & 77.1 & $9.985^{* *}$ & 63.8 & 72.7 & $4.378^{*}$ & 65.9 & 75.3 & $4.895^{*}$ \\
\hline & No & 32.4 & 18.5 & & 31.0 & 28.5 & & 36.3 & 22.9 & & 36.2 & 26.3 & & 34.1 & 24.7 & \\
\hline \multicolumn{17}{|l|}{$\begin{array}{l}\text { Staying } \\
\text { Anonymous }\end{array}$} \\
\hline & Yes & 70.8 & 86.1 & $10.186^{* *}$ & 73.5 & 74.7 & 0.071 & 69.3 & 78.8 & $5.313^{*}$ & 66.2 & 77.7 & $6.483^{*}$ & 70.6 & 77.8 & 3.112 \\
\hline & No & 29.2 & 13.9 & & 26.5 & 25.3 & & 30.7 & 21.2 & & 33.8 & 22.3 & & 29.4 & 22.2 & \\
\hline \multicolumn{17}{|l|}{$\begin{array}{l}\text { Feel } \\
\text { Belonged }\end{array}$} \\
\hline & Yes & 62.5 & 74.1 & $4.900 *$ & 69.9 & 63.7 & 1.464 & 65.1 & 65.3 & 0.002 & 68.5 & 63.9 & 0.848 & 64.5 & 65.8 & 0.092 \\
\hline & No & 37.5 & 25.9 & & 30.1 & 36.3 & & 34.9 & 34.7 & & 31.5 & 36.1 & & 35.5 & 34.2 & \\
\hline
\end{tabular}

Note: $* p<0.05, * * p<0.01$.

Similarly, participants who were more intentional or less intentional in their disclosures, or disclosed more positively or more negatively were also more likely to agree that attachment towards Facebook is unrealistic.

Those who agree that it was unbeneficial to share problems with a Facebook friend, consist of individuals who were more intentional or less intentional, more positive or more negative, more open or less open, honest or less honest in their Facebook disclosure.

Unsurprisingly, participants who were more intentional or less intentional in their disclosure, disclosed more positively or more negatively, shared more intimately or less intimately, all agreed that they felt safer to stay anonymous in the Facebook community.

Lastly, participants who were more intentional or less intentional in their disclosure were more likely to agree to feel belonged to the Facebook community than those who disagree.

\section{DISCUSSION}

Interestingly, results from this study showed that although most of the Facebook users expressed their cautiousness and reservation in their disclosure behaviours, there was a high percentage (roughly 73\% males and 60\% females) of participants who agreed that they feel that they belonged to the Facebook community.

Consistently, most of the participants, regardless if they were aware/not aware of their intent of disclosure; disclose more positively or more negatively about themselves; disclose more intimately or less intimately about themselves; disclosure honestly or less honestly, most of them agreed that Facebook was not a stable community, it was not realistic to become attached to the Facebook community, staying anonymous was safer, and that they belong to this Facebook community.

It seems safer for Facebook users to stay anonymous, so that they could freely express themselves. This is suggested by Zhao and his associates [16] that chosen identity is a kind of self expression. Perhaps it is the new trend of development among teenagers and young adults. It is an evolution of online interaction and high tech communication. They are using high tech communication to stay connected with the people they already know, for searching out information about their interest and pursuing goals, at the same time protecting themselves from any possible harm. The motive for interaction was then satisfied by the instant and effective communication mode. Stable bonds are not expected.

According to Brint's definition of community [7], it is possible to have a sense of community even in communities with large numbers of members, because the shared activities and beliefs will determine the sense of community. Perhaps this can serve as an explanation for the discrepancies found in this study.

\section{CONCLUSION}

Community is an aspiration, most people yearn to belong. Contemporary Facebook users are no exception. Therefore using great caution, they manage to express themselves and maintain connections. Most importantly, they feel a satisfying sense of belongings, however, transient it may be.

\section{ACKNOWLEDGMENT}

We would like to express our gratitude to UTAR Opinion Poll Research Committee for giving us permission to use the data collected 


\section{REFERENCES}

[1] A. L. Blanchard and M. L. Markus, "The experienced 'Sense' of a virtual community: characteristics and process," Database for Advances in Information System, vol. 35 no. 1, pp. 65-79, Winter 2004.

[2] A. Acquisti and R. Gross. Imagined communities: Awareness, Information Sharing and Privacy on the Facebook, PET, pp. 1-22, 2006.

[3] S. E. Mustafa and Z. Hamzah, "Online social networking: A new form of social interaction," International Journal of Social Science and Humanity, Vol. 1 no. 2, pp. 96-104, July 2011.

[4] A. L. Blanchard and M. L. Markus, "The experienced "Sense" of a virtual community: characteristics and processes," The Data Basa for Advances in Information System, Winter 2004, vol. 35, no. 1, pp. 65-79

[5] Z. Bauman, Liquid Modernity, Cambridge, Polity, 2011.

[6] F. Tonnies, "Gemeinschaft and gesellschaft," in the Sociology of Community, C. Bell and H. Newby Eds., London: Frank Cass and Co. Ltd, pp. 7-12, 1967.

[7] S. Brint. (2001). Gemeinschaft Revisited: A critique and reconstruction of the community concept. Sociology theory. Retrieved on March 30 2012. [Online]. Available: http://search.asanet.org/images/members/docs/pdf/featured/soth125.p df

[8] Z. Bauman, Community: Seeking Safety in an Insecure World, Cambridge, Polity, 2003.

[9] M. J. Metzger, "Privacy, trust and disclosure: exploring barriers to electronic commerce," Journal of Computer-mediated communication, vol. 9 , no. 4, 2004.

[10] C. Dwyer and S. Hiltz, "Trust and privacy concern within social networking sites: a comparison of Facebook and my space," in Proc. Americas Conference on Information System (AMCIS), AMCIS 2007 Proceedings.

[11] P. Norris, "The bridging and bonding role of online communities," The Harvard International Journal of Press/Politics, vol. 7, no. 3, pp. 3-13. Jul 1, 2002.

[12] J. Bonnear, J. Anderson, and G. Danezis, "Prying data out of a social network," in Proc. International Conference on Advances in Social Network Analysis and Mining, vol. 10, pp. 249-254, 2009.

[13] J. Bryce and M. Klang, "Young people, disclosure of personal informational and online privacy: control, choice and consequences," Informational Security Technical Report, vol. 14, pp. 160-166, 2009.

[14] T. A. Pempek, Y. A. Yermolayeva, and S. L. Calvert, "College students' social networking experiences on Facebook," Journal of Applied Developmental Psychology, vol. 30, pp. 227-238, 2009.

[15] L. R. Wheeless and J. Grotz, "Conceptualization and measurement of reported self-disclosure," Human Communication Research, vol. 4, no. 2, pp. 143-157.

[16] S. Zhao, S. Grasmuck, and J. Martin, "Identity construction on Facebook: digital empowerment in anchored relationships," Computers in Human Behaviour, vol. 24, pp. 1816-1836, 2008.

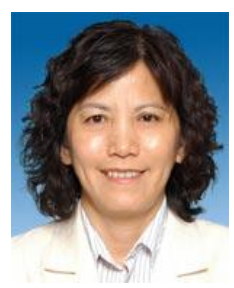

Jin Kuan Kok was born in Malaysia. She holds BA in Chinese literature from National Taiwan University, master in education (guidance and counselling), Durham University, England, UK and doctorate degree in education, Durham University, England, UK.

She has extensive counselling experience working with young people and family. Her present professional occupation: is an assistant professor, Department of Psychology and Counselling, Faculty of Arts and Social Science, Universiti Tunku Abdul Rahman.

Dr. Kok is the principal researcher for many projects for the Centre of Applied Psychology at UTAR and her research interests are narrative inquiry, teenage suicide and depression, narrative approach in counselling and youth studies.
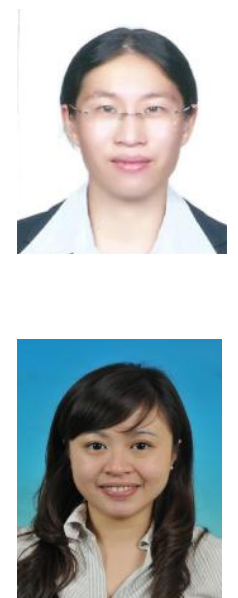

Wan Ying Lee received her bachelor of social science (hons) psychology, from Universiti Tunku Abdul Rahman (UTAR), Malaysia in 2009. She is currently serving as a tutor and pursuing her masters of philosophy (social science) in UTAR. Her research interests include human development, internet studies and education.

Shue Ling Chong received her bachelor of arts (hons) psychology, from UCSI University in 2011. She is currently pursuing her doctor of philosophy (psychology and child development) in Universiti Putra Malaysia. Her research interests include child and adolescent psychology, youth study, positive psychology, and health psychology. 